\title{
Ryanodine facilitates calcium-dependent release of transmitter at mouse neuromuscular junctions
}

\author{
${ }^{1}$ Masakazu Nishimura, Kikuko Tsubaki, Osamu Yagasaki \& *Katsuaki Ito
}

Department of Veterinary Pharmacology, College of Agriculture, University of Osaka Prefecture, Sakai, Osaka 591, *Department of Veterinary Pharmacology, Faculty of Agriculture, University of Miyazaki, Miyazaki 889-21, Japan

1 Quantal release of transmitter was measured intracellularly at mouse neuromuscular junctions in the presence and absence of ryanodine (Rnd).

2 Rnd at concentrations up to $1 \mu \mathrm{M}$ did not significantly alter the frequency of miniature endplate potentials (m.e.p.ps) in the presence or absence of $\mathrm{Ca}^{2+}$, suggesting that $\mathrm{Rnd}$ is unlikely to alter the internal concentration of $\mathrm{Ca}^{2+}\left(\left[\mathrm{Ca}^{2+}\right]_{i}\right)$ at rest.

3 In a high- $\mathrm{K}^{+}(10 \mathrm{~mm})$ bathing solution, Rnd further potentiated the facilitatory effect of $\mathrm{Ca}^{2+}$ on the frequency $\left(F, s^{-1}\right)$ of m.e.p.ps. Rnd shifted the relationship between $\ln (F)$ and $\ln \left[\mathrm{Ca}^{2+}\right]_{0}$ to lower concentrations.

4 In a high- $\mathrm{Mg}^{2+}$ bathing solution, Rnd did not affect the frequency of m.e.p.ps at any value of $\left[\mathrm{Ca}^{2+}\right]_{0}$. However, Rnd slightly but significantly increased the quantal content (m) of e.p.ps. It shifted the relationship between $\ln (\mathrm{m})$ and $\ln \left[\mathrm{Ca}^{2+}\right]_{0}$ to lower concentrations. These results suggest that Rnd potentiates the quantal release of transmitter after depolarization of the membrane or nerve impulse, in keeping with the cooperativity of $\mathrm{Ca}^{2+}$ at the active site.

5 A series of two closely spaced nerve impulses produced a facilitation of transmitter release, as judged by the quantal content $(\mathrm{m} 2)$ of the second response in relation to that of the first one $(\mathrm{m} 1), \mathrm{m} 2 / \mathrm{m} 1$. Rnd did not change the ratio $\mathrm{m} 2 / \mathrm{m} 1$. Thus $\mathrm{Rnd}$ is unlikely to affect the rapid phase of the sequestration of $\mathrm{Ca}^{2+}$ inside the nerve terminal.

6 High levels of $\mathrm{K}^{+}(5 \mathrm{~mm})$ and caffeine $(2 \mathrm{~mm})$ potentiated both modes of transmitter release, in a manner dependent on $\left[\mathrm{Ca}^{2+}\right]_{0}$. Caffeine did not potentiate facilitation of transmitter release.

7 These results indicate that Rnd facilitates the quantal release of transmitter presumably via an increase in $\left[\mathrm{Ca}^{2+}\right]_{\mathrm{i}}$ by a manner different from that of high- $\mathrm{K}^{+}$or caffeine. The results suggest that Rnd probably affects calcium turnover in neuronal cells.

\section{Introduction}

Ryanodine (Rnd) is an alkaloid extracted from the South American plant Ryania speciosa (Jenden \& Fairhurst, 1969). It is widely accepted that Rnd specifically affects the calcium release mechanism of sarcoplasmic reticulum (SR) in a variety of muscles (Sutko \& Willerson, 1980; Sutko et al., 1985; Ito et al., 1986; Su, 1987). Biochemical or electrophysiological studies revealed that this agent locks the $\mathrm{Ca}^{2+}$ release channel of SR in an open state (Fleischer et al., 1985; Meissner, 1986; Rousseau et al., 1987), although it at a high concentration might inhibit the opening of the channel under some conditions (Meissner, 1986; Lattanzio et al., 1987). Several groups reported that the action of Rnd was accelerated by the existence of certain levels of $\mathrm{Ca}^{2+}$ outside SR and was attenuated by $\mathrm{Mg}^{2+}$ (Meissner, 1986; Lattanzio et al., 1987; Hisayama \& Takayanagi, 1988).

As proposed in the 'calcium hypothesis' (Katz, 1969), the release of transmitter at the motor nerve terminal is mediated by $\mathrm{Ca}^{2+}$ in nerve ending cytoplasm (Katz \& Miledi, 1965). A growing body of evidence indicates that the nerve terminal has some sites to store $\mathrm{Ca}^{2+}$ (Blaustein et al., 1980; Brinley, 1980). Those sites are predominantly endoplasmic reticulum (ER) and the mitochondria. Although the functional role of the ER is supposed to be similar to that of the SR in muscle cells in some respects (Blaustein et al., 1980; Brinley, 1980), the mechanism by which it regulates intracellular calcium is not so clear as that of the SR. In particular clarification is required as to whether calcium handling by ER modifies the transmitter release from nerves. Recently, Rnd has been demonstrated to inhibit caffeine-induced $\left[\mathrm{Ca}^{2+}\right]_{\mathrm{i}}$ transients in sympathetic neurones (Thayer et al., 1988). If it has some

\footnotetext{
${ }^{1}$ Author for correspondence.
}

action on functions of ER in the motor nerve terminals, this agent could be a useful tool for a study of the regulatory mechanism of ER on transmitter release. Thus, we examined the effect of Rnd on the rate of quantal release of transmitter at mouse neuromuscular junctions. The results show that Rnd facilitates the release of transmitter quanta in a manner that depends on $\left[\mathrm{Ca}^{2+}\right]_{0}$ and depolarization of the nerve terminals.

\section{Methods}

Experiments were performed on preparations of isolated left hemidiaphragm from male $d d Y$ mice of 9 to 12 weeks of age. The preparation was pinned to a silicone resin which lined the bottom of a plastic chamber of about $30 \mathrm{ml}$ capacity, and was soaked in Krebs-Ringer solution. The solution was constantly recirculated by means of an $\mathrm{O}_{2}$ lift system. The circulating solution had the following eomposition (mM): $\mathrm{NaCl} 136, \mathrm{KCl}$ $5, \mathrm{CaCl}_{2} 2, \mathrm{MgCl}_{2} 1, \mathrm{NaHCO}_{3} 15$ and glucose 11. To depolarize the presynaptic endings (Liley, 1956), the preparation was soaked in Krebs-Ringer solution in which $10 \mathrm{mM} \mathrm{NaCl}$ was replaced by $10 \mathrm{mM} \mathrm{KCl}\left(10 \mathrm{mM} \mathrm{K}{ }^{+}\right)$. The concentration of $\mathrm{Ca}^{2+}$ in this solution varied from nominally 0 (no addition of $\mathrm{CaCl}_{2}$ and EGTA [ethylene glycol-bis $(\beta$-aminoethyl ether $\mathrm{N}, \mathrm{N}, \mathrm{N}^{\prime}, \mathrm{N}^{\prime}$-tetraacetic acid]) to 0.5 millimolar. The preparation was equilibrated in the $10 \mathrm{mM} \mathrm{K}^{+}$solution for at least $30 \mathrm{~min}$ before addition of any agent. A bathing solution which contained $5 \mathrm{mM} \mathrm{Mg}^{2+}$ was also prepared, containing 0.4 $0.8 \mathrm{mM}$ in $\mathrm{Ca}^{2+}$, for measurements of endplate potentials (e.p.ps) as well as miniature endplate potentials (m.e.p.ps). A high- $\mathrm{Mg}^{2+}$ bathing solution containing hypertonic $5 \mathrm{mM} \mathrm{KCl}$ $\left.(5 \mathrm{mM} \mathrm{K})^{+}\right)$or $2 \mathrm{mM}$ caffeine was also prepared. The bathing solutions were bubbled with a mixture of $95 \% \mathrm{O}_{2}$ and $5 \%$ 
$\mathrm{CO}_{2}$ and maintained at $\mathrm{pH} 7.3$ and at $36^{\circ} \mathrm{C}$. The temperature of the bath was monitored by a thermister (Shibaura Electric Co, Model MGA-II) and held constant by means of an external water jacket and a thermoregulatory device (Taiyo, Thermominder Mini 80) during each experiment.

Intracellular recordings were made with glass microcapillary electrodes, filled with $3 \mathrm{M} \mathrm{KCl}$, with resistance of 5 to 8 megohms. The electrode was inserted into fibers near endplate regions. The signals were led through a high-impedance, unity-gain preamplifier (Nihon Kohden, Tokyo, MEZ-8201), displayed on an oscilloscope (Nihon Kohden, VC-10) and stored on an FM instrumentation tape recorder (Nihon Kohden, RMG-5204).

M.e.p.ps of $0.1 \mathrm{mV}$ or larger amplitide were counted by a computer (Nihon Kohden, DAB-1100). M.e.p.ps were recorded for successive periods of $1 \mathrm{~min}$ after exposure to a given solution; from these data the mean frequency of m.e.p.ps was calculated. E.p.ps were evoked by stimulation of the phrenic nerve with 128 or 256 square pulses of $0.1 \mathrm{~ms}$ duration and supramaximal voltage of $1 \mathrm{~Hz}$ through a suction electrode in a high- $\mathrm{Mg}^{2+}$ bathing solution with low concentrations of $\mathrm{Ca}^{2+}(0.4$ to $0.8 \mathrm{mM})$. In other experiments, the nerve trunk was electrically conditioned to change neuronal reactivity. A series of two closely spaced nerve stimuli with an interval of $4 \mathrm{~ms}$ between them were given 128 or 256 times at intervals of $1.5 \mathrm{~s}$ in a $5 \mathrm{mM} \mathrm{Mg} \mathrm{Mg}^{2+}$ bathing solution that contained $0.6 \mathrm{~mm}$ $\mathrm{Ca}^{2+}$, after measurement of m.e.p.ps for about $1 \mathrm{~min}$. This trial resulted in e.p.ps of the first and second responses. All the measurements in the presence of Rnd were initiated $10 \mathrm{~min}$ after its addition and terminated within $40 \mathrm{~min}$ thereafter to avoid dislocation of the electrode from the endplate region due to Rnd-induced contracture.

The quantal content $(m)$ was estimated by the method of failures from

$$
m=\log _{e}\left(N / N_{0}\right),
$$

where $N=$ number of trials and $N_{0}=$ number of failures (Crawford, 1974). Student's $t$ tests were used for statistical analyses and a probability of less than 0.05 was deemed statistically significant.

Ryanodine was purchased from S. B. Penick Lyndhurst, NJ, U.S.A. (Lot No. 704R WP-1). All other chemicals were of analytical grade.

\section{Results}

\section{Effect on the frequency of m.e.p.ps}

M.e.p.ps were measured randomly at 5 endplates in each of 8 preparations in a standard bathing solution or in a $\mathrm{Ca}^{2+}$-free bathing solution (Figure 1). The mean frequency $\left(\mathrm{s}^{-1}\right)$ of m.e.p.ps was slightly reduced in the $\mathrm{Ca}^{2+}$-free solution. Rnd at
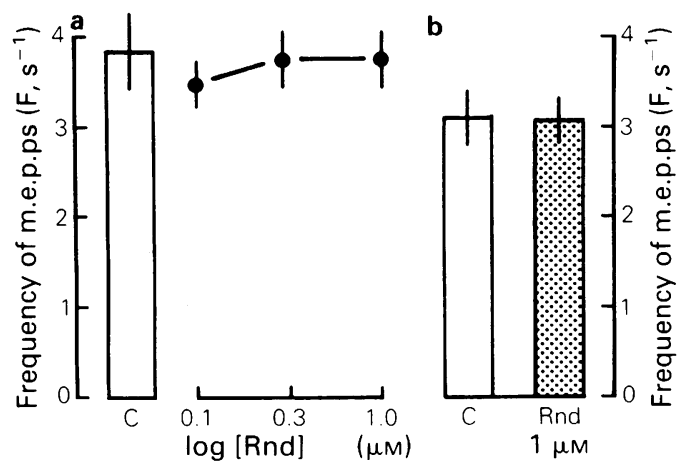

Figure 1 Effects of ryanodine (Rnd) at concentrations up to $1 \mu \mathrm{M}$ on the frequency $\left(\mathrm{F}, \mathrm{s}^{-1}\right)$ of m.e.p.ps in mouse diaphragm muscles in a standard bathing solution (a) and in a $\mathrm{Ca}^{2+}$-free solution (b). Vertical bars show s.e.mean of results from 40 endplates in 8 preparations ( 5 endplates each). C: control. Rnd: ryanodine. concentrations up to $1 \mu \mathrm{M}$ did not significantly affect the frequency of m.e.p.ps in the presence or absence of $\left[\mathrm{Ca}^{2+}\right]_{0}$ within the first 10 to $50 \mathrm{~min}$ of the exposure period. When a preparation was exposed to Rnd for more than $60 \mathrm{~min}$, a gradual increase in muscle tonus was frequently observed. This contracture made it impossible to maintain continuous recordings of the potential changes at an endplate by dislodging the electrode. Thus, measurements of the potential changes were discontinued within $50 \mathrm{~min}$ of the start of exposure to Rnd.

Depolarization potentiates the effect of $\left[\mathrm{Ca}^{2+}\right]_{0}$ on the spontaneous release of transmitter quanta. The effect of Rnd was examined on the frequency of m.e.p.ps in a $10 \mathrm{mM} \mathrm{K}^{+}$ bathing solution that contained various levels of $\left[\mathrm{Ca}^{2+}\right]_{0}$, nominally $0,0.125,0.25$ and $0.5 \mathrm{~mm}$. During experiments in the presence of Rnd we measured m.e.p.ps at several endplates from 10 to $50 \mathrm{~min}$ after the start of exposure to this agent, then calculated the frequency of m.e.p.ps. The $\left[\mathrm{Ca}^{2+}\right]_{0}$-dependent increase in the frequency of m.e.p.ps in $10 \mathrm{mM} \mathrm{K}^{+}$bathing solution was calculated by subtracting the mean value of the frequency of m.e.p.ps measured in $\mathrm{Ca}^{2+}$. free, $10 \mathrm{mM} \mathrm{K}^{+}$solution from each value measured in the presence of $\left[\mathrm{Ca}^{2+}\right]_{0}$, because m.e.p.ps were detectable in the absence of $\left[\mathrm{Ca}^{2+}\right]_{0}$. In experiments which were performed in the presence of Rnd, the mean frequency of m.e.p.ps in the presence of Rnd and in the absence of $\left[\mathrm{Ca}^{2+}\right]_{0}$ was used to correct for m.e.p.ps that occurred in the presence of Rnd with increasing $\left[\mathrm{Ca}^{2+}\right]_{0}$. The frequency of m.e.p.ps increased with the increase in $\left[\mathrm{Ca}^{2+}\right]$ in a nonlinear fashion (Figure 2a). Such a facilitating effect of $\left[\mathrm{Ca}^{2+}\right]_{0}$ was further potentiated by Rnd. Rnd significantly elevated the mean value of the frequency $\left(\mathrm{F}, \mathrm{s}^{-1}\right)$ at every $\left[\mathrm{Ca}^{2+}\right]_{0}$. To determine whether Rnd exerts its effect on the spontaneous release of transmitter without changing the cooperativity of $\mathrm{Ca}^{2+}$, as does sodium salicylate (Nishimura et al., 1989), the effect of Rnd on the relationship between $\ln (\mathrm{F})$ and $\ln \left(\left[\mathrm{Ca}^{2+}\right]_{0}\right)$ was examined. Figure $2 b$ shows the effect of Rnd on the curves that relate $\ln (\mathrm{F})$ to $\ln \left(\left[\mathrm{Ca}^{2+}\right]_{0}\right)$. In the absence of $\mathrm{Rnd}$, the relationship between $\ln (\mathrm{F})$ and $\ln \left(\left[\mathrm{Ca}^{2+}\right]_{0}\right)$ was linear. The only effect of Rnd was to shift the curve to the left (towards lower values of $\ln \left(\left[\mathrm{Ca}^{2+}\right]_{0}\right)$, suggesting that $\mathrm{Rnd}$ facilitates the release of transmitter without changing the cooperativity of $\mathrm{Ca}^{2+}$.

\section{Effect on the quantal content of e.p.ps}

E.p.ps were evoked in a $\mathbf{M g}^{2+}(5 \mathrm{mM})$ bathing solution that contained low levels of $\left[\mathrm{Ca}^{2+}\right]_{0}(0.4$ to $0.8 \mathrm{~mm})$, with or without Rnd. Measurements of e.p.ps in the presence of Rnd
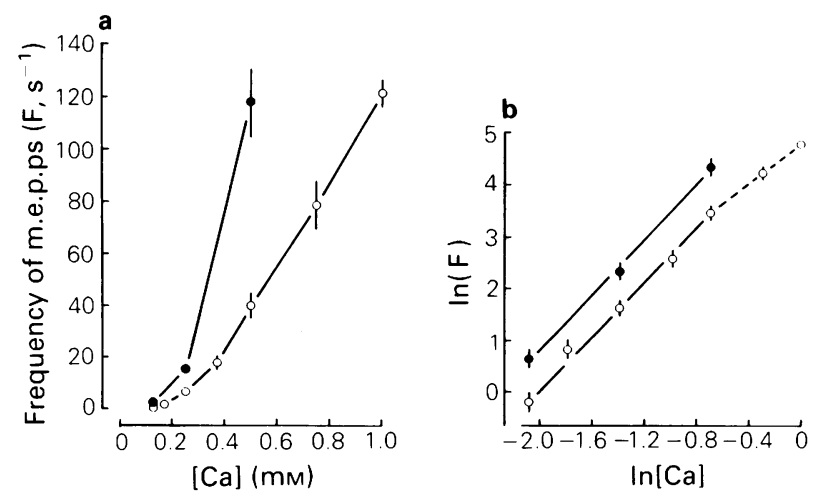

Figure 2 (a) Effect of $1 \mu \mathrm{M}$ ryanodine (Rnd) on the frequency $\left(\mathrm{F}, \mathrm{s}^{-1}\right)$ of m.e.p.ps in mouse diaphragm preparations in high- $\mathrm{K}^{+}(10 \mathrm{~mm})$ bathing solutions that contained various concentrations of $\mathrm{Ca}^{2+}$. Vertical bars show s.e.mean, where possible, of observations from 40 endplates in 8 muscles ( 5 endplates in each muscle). (b) Natural logarithmic plot of the data used to generate (a). Ordinate scale: natural logarithmic values of the frequency of m.e.p.ps, $\ln (\mathrm{F})$. Abscissa scale: natural logarithmic values of $\left[\mathrm{Ca}^{2+}\right]_{0}(\mathrm{mM}), \ln \left[\mathrm{Ca}^{2+}\right]_{0} \cdot(\bigcirc)$ : Rnd; (O): control. 
were initiated $10 \mathrm{~min}$ after the addition of Rnd to solutions and were continued for the subsequent $40 \mathrm{~min}$ at several endplates. M.e.p.ps were measured at every endplate before e.p.ps were evoked in the high- $\mathbf{M g}^{2+}$ bathing solution (Figure 3) The mean frequency of m.e.p.ps was slightly increased with an elevation of $\left[\mathrm{Ca}^{2+}\right]_{0}$ in the presence and in the absence of Rnd. Rnd did not significantly affect the frequency of m.e.p.ps in this high- $\mathrm{Mg}^{2+}$ bathing solution, an observation similar to that made in the standard bathing solution (Figure 1).

The quantal content of e.p.ps was estimated by the method of failures (see Methods) (Figure 4a). The evoked release increased with an elevation of $\left[\mathrm{Ca}^{2+}\right]_{0}$ in a nonlinear fashion. Rnd further and significantly $(P<0.05)$ increased the quantal content $(\mathrm{m})$ at all values of $\left[\mathrm{Ca}^{2+}\right]_{0}$ tested. Values for $\mathrm{m}$ were converted to $\ln (m)$. The value of $\ln (m)$ was plotted against $\ln \left(\left[\mathrm{Ca}^{2+}\right]_{0}\right)$ (Cooke et al., 1973) in the presence and absence of Rnd (Figure 4b). The relationship between $\ln (\mathrm{m})$ and $\ln \left(\left[\mathrm{Ca}^{2+}\right]_{0}\right)$ was linear in the presence and in the absence of Rnd. The curve in the presence of Rnd was slightly but significantly $(P<0.05)$ shifted to lower $\left[\mathrm{Ca}^{2+}\right]_{0}$, as was observed in the case of the frequency of m.e.p.ps.

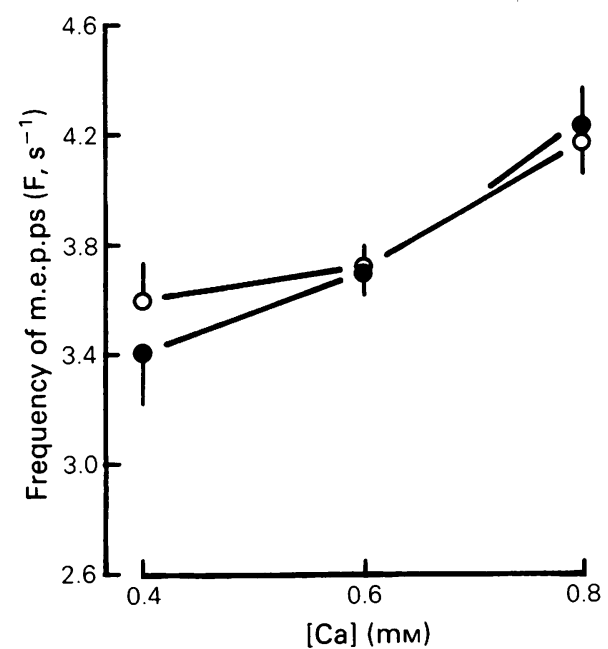

Figure 3 Effect of ryanodine (Rnd) $1 \mu \mathrm{M}$ on the frequency $\left(\mathrm{F}, \mathrm{s}^{-1}\right)$ of m.e.p.ps in mouse diaphragm preparations in high- $\mathrm{Mg}^{2+}(5 \mathrm{mM})$ bathing solutions that contained various levels of $\left[\mathrm{Ca}^{2+}\right]_{0} .(O)$ control; (@) ryanodine. Vertical bars show s.e.mean, where possible of determinations from 273 to 545 endplates in 35 to 65 preparations. The resting rate of quantal release of transmitter did not change in the presence of Rnd.
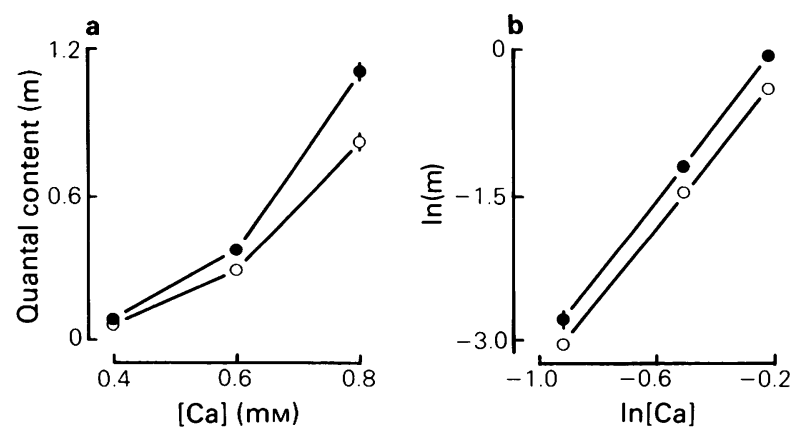

Figure 4 (a) Effect of ryanodine (Rnd) $1 \mu \mathrm{M}$ on quantal content (m) of e.p.ps in mouse diaphragm muscles in high- $\mathrm{Mg}^{2+}(5 \mathrm{mM})$ bathing solutions that contained various levels of $\left[\mathrm{Ca}^{2+}\right]_{0}$. Vertical bars show s.e.mean of results from 273 to 545 endplates in 35 to 65 muscles, where possible. (b) Natural logarithmic plot of the data used to generate (a). (O) Rnd; (O) control. Ordinate scale: natural logarithmic values of quantal content $(\mathrm{m})$ of e.p.ps, $\ln (\mathrm{m})$. Abscissa scale: natural logarithmic values of $\left[\mathrm{Ca}^{2+}\right]_{0}(\mathrm{mM}), \ln \left[\mathrm{Ca}^{2+}\right]_{0}$.
Comparison of the effects of ryanodine with the effects of high $\mathrm{K}^{+}$and caffeine

The effects of $5 \mathrm{~mm} \mathrm{~K} \mathrm{~K}^{+}, 2 \mathrm{~mm}$ caffeine and Rnd on spontaneous and evoked releases of transmitter quanta were compared in high $\mathrm{Mg}^{2+}(5 \mathrm{mM})$ bathing solution containing $0.6 \mathrm{mM} \mathrm{Ca}{ }^{2+}$ (Figure 5). As mentioned above, Rnd did not significantly alter the frequency of m.e.p.ps at resting membrane potentials but significantly $(P<0.05)$ increased quantal content of e.p.ps. Both high $\mathrm{K}^{+}$and caffeine caused significant $(P<0.05)$ increases in both the frequency of m.e.p.ps and the quantal content of e.p.ps. Caffeine caused greater effects on m.e.p.ps than on e.p.ps while high $\mathrm{K}^{+}$showed the opposite relationship. Caffeine and high $\mathrm{K}^{+}$had little effect on the frequency of m.e.p.ps in a $\mathrm{Ca}^{2+}$-free bathing solution.

\section{Effect on facilitation of transmitter release}

Facilitation of transmitter release was elicited by a series of two closely spaced stimuli with an interval of $4 \mathrm{~ms}$ on the nerve trunk. Such paired stimulation was repeated 128 or 256 times, with intervals of $1.5 \mathrm{~s}$, at each endplate. Quantal contents of the first and second e.p.ps were designated as $\mathrm{m} 1$ and $\mathrm{m} 2$. Thus, the facilitation was expressed as $\mathrm{m} 2 / \mathrm{m} 1$ (Figure 6). Measurements in the presence of Rnd or caffeine were initiated $10 \mathrm{~min}$ after their addition and continued for $40 \mathrm{~min}$. The

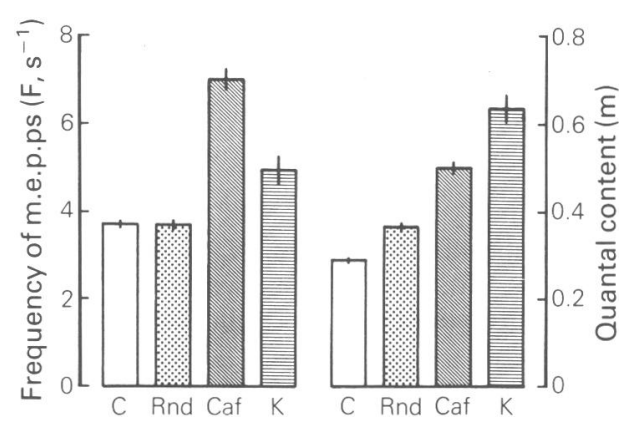

Figure 5 Comparison of effects of ryanodine (Rnd), caffeine (Caf) and high $\mathrm{K}^{+}$on quantal release of transmitter at mouse neuromuscular junctions in a bathing solution that contained $0.6 \mathrm{mM} \mathrm{Ca}^{2+}$ and $5 \mathrm{mM} \mathrm{Mg}^{2+}$. Vertical bars show s.e.mean of observations from 177 to 927 endplates in 10 to 40 muscles. C: control. Rnd: $1 \mu \mathrm{M}$ ryanodine. Caf: $2 \mathrm{~mm}$ caffeine. $\mathrm{K}: 5 \mathrm{~mm} \mathrm{~K}{ }^{+}$.

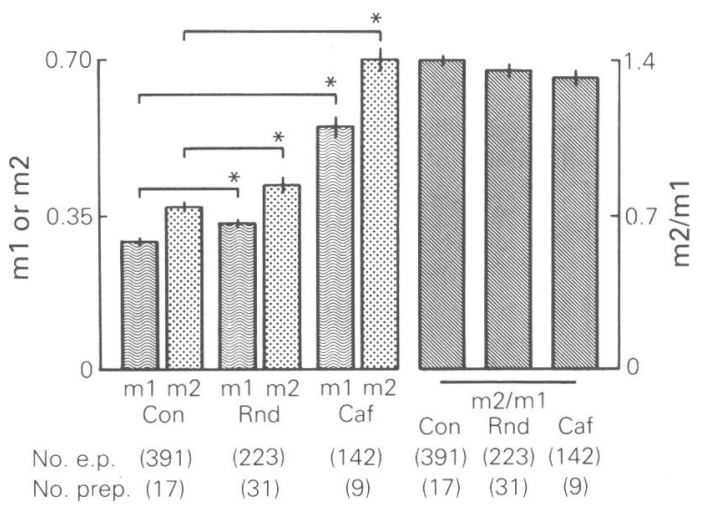

Figure 6 Effects of ryanodine (Rnd) and caffeine (Caf) on facilitation of transmitter release at mouse neuromuscular junctions in a bathing solution that contained $0.6 \mathrm{mM} \mathrm{Ca}^{2+}$ and $5 \mathrm{mM} \mathrm{Mg}^{2+}$; Con: control. The phrenic nerve was stimulated by paired pulses with a $4 \mathrm{~ms}$ interval. These stimuli produced quantal contents of the first $(\mathrm{m} 1)$ and second $(\mathrm{m} 2)$ e.p.ps. The facilitation is shown as the ratio of $\mathrm{m} 2 / \mathrm{m} 1$. No. e.p., numbers of endplates tested. No. prep., numbers of preparations used. Vertical bars show s.e.mean. ${ }^{*} P<0.05$. 
mean value of $\mathrm{m} 2$ was always larger than that of $\mathrm{m} 1$ in each case, causing the mean value of $\mathrm{m} 2 / \mathrm{m} 1$ to be larger than 1 . Both $1 \mu \mathrm{M}$ Rnd and $2 \mathrm{mM}$ vaffeine significantly $(P<0.05)$ increased the value of $\mathrm{ml}$ as indicated above. Since their stimulatory effects also appeared on the second e.p.ps (m2), the ratio $\mathrm{m} 2 / \mathrm{m} 1$ was never observed to increase in the presence of either agent.

\section{Discussion}

$\left[\mathrm{Ca}^{2+}\right]_{\mathrm{i}}$ plays a central role in the process of release of transmitter quanta (Augustine et al., 1987). Present experiments indicated that $\mathrm{Rnd}$ facilitates the quantal release of transmitter only when the nerve terminal is depolarized and $\left[\mathrm{Ca}^{2+}\right]_{0}$ is greater than $0.125 \mathrm{~mm}$. Such effects appear to be achieved without any alteration in the slope of the curve for the relationship between $\ln (\mathrm{F})$ and $\ln \left(\left[\mathrm{Ca}^{2+}\right]_{0}\right)$ or $\ln (\mathrm{m})$ and $\ln \left(\left[\mathrm{Ca}^{2+}\right]_{0}\right)$. It has been suggested that the non-linear dependence of quantal release of $\left[\mathrm{Ca}^{2+}\right]$ o shows cooperativity of $\mathrm{Ca}^{2+}$ at the active site (Jenkinson, 1957; Rahamimoff, 1976). Our data suggest that Rnd probably accomplishes its effect without changing the cooperativity of $\mathrm{Ca}^{2+}$, and that Rnd causes a facilitation in the release process depending upon $\left[\mathrm{Ca}^{2+}\right]_{0}$. Thus, according to the calcium hypothesis (Katz, 1969), the effects of Rnd are probably due to an increase in available $\left[\mathrm{Ca}^{2+}\right]_{\mathrm{i}}$.

If an increase in $\left[\mathrm{Ca}^{2+}\right]_{\mathrm{i}}$ is actually caused by $\mathrm{Rnd}$, the question arises as to the source of this $\mathrm{Ca}^{2+}$. Many sources have been proposed for increases in $\mathrm{Ca}^{2+}$ in the nerve terminal: (1) an influx through voltage-gated channels; (2) release from internal storage site(s); (3) inhibition of mechanism(s) for sequestrating $\mathrm{Ca}^{2+}$ in internal structures; and (4) inhibition of some extrusion mechanism(s) (Rahamimoff, 1976). The results indicate that Rnd never stimulates quantal release of transmitter at the resting state. In the sympathetic neurones, Rnd affects intracellular $\mathrm{Ca}^{2+}$ turnover in the presence of caffeine (Thayer et al., 1988). Thus, it is unlikely that Rnd can increase $\left[\mathrm{Ca}^{2+}\right]_{\mathrm{i}}$ at rest. Furthermore, other trials showed that Rnd, as well as caffeine, did not alter the ratio of $\mathrm{m} 2 / \mathrm{m} 1$ when a series of two closely spaced nerve impulses was adopted. This type of facilitation has been interpreted to be caused by 'residual $\mathrm{Ca}^{2+}$ which outlasts a presynaptic activation and enhances the response to a subsequent impulse (Katz \& Miledi, 1968; Rahamimoff, 1968; Charlton et al., 1982). Some finite period of time is required for sequestration of extrusion of $\mathrm{Ca}^{2+}$ which enters the nerve terminal during nerve impulse. The subsequent stimulation given when the postulated residual $\mathrm{Ca}^{2+}$ exists in the nerve terminal would potentiate the second

\section{References}

AOKI, S. \& ITO, K. (1988). Time- and use-dependent inhibition by ryanodine of caffeine-induced contraction of guinea-pig aortic smooth muscle. Biochem. Biophys. Res. Commun., 154, 219-226.

AUgustine, G.J., CHARLTON, M.P. \& SMITH, S.J. (1987). Calcium action in synaptic transmitter release. Ann. Rev. Neurosci., 10, 633693.

BlaUSTEIN, M.P., RATZlAFF, R.W. \& SCHWEITZER, E.S. (1980). Control of intracellular calcium in presynaptic nerve terminals. Fed. Proc., 39, 2790-2795.

BRINLEY, Jr., F.J. (1980). Regulation of intracellular calcium in squid axons. Fed. Proc., 39, 2778-2782.

CHARLTON, M.P., SMITH, S.J. \& ZUCKER, R.S. (1982). Role of presynaptic calcium ions and channels in synaptic facilitation and depression at the squid giant synapse. J. Physiol., 323, 173-193.

COOKE, J.D., OKAMOTO, K. \& QUASTEL, D.M.J. (1973). The role of calcium in depolarization-secretion coupling at the motor nerve terminal. J. Physiol., 228, 459-497.

CRAWFORD, A.C. (1974). The dependence of evoked transmitter release on external calcium ions at very low mean quantal contents. J. Physiol., 240, 255-278.

FLEISCHER, S., OGUNBUNMI, E.M., DIXON, M.C. \& FLEER, A.M. (1985). Localization of $\mathrm{Ca}^{2+}$ release channels with ryanodine in response of quantal release. Consistent with this suggestion is the observation that the ratio of $\mathrm{m} 2 / \mathrm{m} 1$ is larger than 1 . If Rnd inhibits the sequestering process for internal $\mathrm{Ca}^{2+}$, such an effect would cause an increase in this ratio. However, the ratio of $\mathrm{m} 2 / \mathrm{m} 1$ was never changed in the presence of Rnd. Thus, it is unlikely at least that Rnd inhibits the sequestration of $\mathrm{Ca}^{2+}$ involved in this type of facilitation.

We demonstrated the dependence of the effect of Rnd on depolarization of the nerve terminal as well as on values of $\left[\mathrm{Ca}^{2+}\right]_{0}$ greater than $0.125 \mathrm{~mm}$. Ca channels at presynaptic terminals function to transduce changes in membrane potential into an influx of $\mathrm{Ca}^{2+}$ down their electrochemical gradient (Augustine et al., 1987). Therefore the effect of Rnd on transmitter release seems to be associated with depolarization or a transmembrane $\mathrm{Ca}^{2+}$ influx. In this regard, two possibilities arise, one of which is that Rnd augments the transmembrane $\mathrm{Ca}^{2+}$ influx upon activation of plasmalemmal $\mathrm{Ca}^{2+}$ channels. However, a possibility that Rnd has a direct action on plasmalemmal $\mathrm{Ca}^{2+}$ channels in cardiac and vascular smooth muscles was excluded (Mitchell et al., 1984; Ito et al., 1986) so that Rnd is unlikely to affect at least the L-type $\mathrm{Ca}^{2+}$ channel. No evidence was obtained as to whether Rnd acts on $\mathrm{N}$-type $\mathrm{Ca}^{2+}$ channels which exist in nerve membranes. This should be clarified in a future study. A second possibility is that Rnd may interfere with the calcium handling of an intracellular organelle. If ER behaves similarly to $S R$ in releasing $\mathrm{Ca}^{2+}$ in response to depolarization or $\mathrm{Ca}^{2+}$ influx and if $R$ nd affects the $\mathrm{Ca}^{2+}$ release mechanism, the substance could alter the transmitter release from nerve terminals. Rnd was shown to lock the $\mathrm{Ca}^{2+}$ release channel of skeletal and cardiac SR in an open state (Fleischer et al., 1985; Rousseau et al., 1987; Lai et al., 1988) thereby allowing $\mathrm{Ca}^{2+}$ to leak out from SR. The action of Rnd is dependent on the history of the opening of the $\mathrm{Ca}^{2+}$ release channel (Sutko et al., 1985; Aoki \& Ito, 1988; Iino et al., 1988). These features of the action of $R$ nd in muscles can explain its mode of action on transmitter release observed in this study. Attenuation of the Rnd effect by high $\mathrm{Mg}^{2+}$ is also similar to the action of Rnd observed in muscles (Meissner, 1986; Meissner \& Henderson, 1987). Therefore, it is likely that Rnd has an intracellular action, at least part of which is analogous to its action on muscle SR. Indeed Rnd has been shown to inhibit caffeineinduced $\left[\mathrm{Ca}^{2+}\right]_{\mathrm{i}}$ transients in sympathetic neurones (Thayer et al., 1988).

This study has demonstrated that Rnd can affect quantal release of transmitter depending on $\mathrm{Ca}^{2+}$. Further study is needed to determine if Rnd specifically acts on ER and if this agent can be used as a specific tool for a study of intracellular calcium regulatory mechanisms in the nerve terminal. junctional terminal cisternae of sarcoplasmic reticulum of fast skeletal muscle. Proc. Natl. Acad. Sci., U.S.A., 82, 7256-7259.

HISAYAMA, T. \& TAKAYANAGI, I. (1988). Ryanodine: its possible mechanism of action in the caffeine-sensitive calcium store of smooth muscle. Pflügers Arch., 412, 376-381.

IINO, M., KOBAYASHI, T. \& ENDO, M. (1988). Use of ryanodine for functional removal of the calcium store in smooth muscle cells of the guinea-pig. Biochem. Biophys. Res. Commun., 152, 417-422.

ITO, K., TAKAKURA, S., SATO, K. \& SUTKO, L. (1986). Ryanodine inhibits the release of calcium from intracellular stores in guinea pig aortic smooth muscle. Circ. Res., 58, 730-734.

JENDEN, D.J. \& FAIRHURST, A.S. (1969). The pharmacology of ryanodine. Pharmacol. Rev., 21, 1-25.

JENKINSON, D.H. (1957). The nature of the antagonism between calcium and magnesium ions at the neuromuscular junction. $J$. Physiol., 138, 434-444.

KATZ, B. (1969). The Release of Neural Transmitter Substances. pp. 1-60. Springfield, Illinois: Charles C. Thomas.

KATZ, B. \& MILEDI, R. (1965). The effect of calcium on acetylcholine release from motor nerve terminals. Proc. $R$. Soc. B., 161, 495-503.

KATZ, B. \& MILEDI, R. (1968). The role of calcium in neuromuscular facilitation. J. Physiol., 195, 481-492. 
LAI, F.A., ANDERSON, K., ROUSSEAU, E., LIU, Q.-Y. \& MEISSNER, G. (1988). Evidence for a calcium channel within the ryanodine receptor complex from cardiac sarcoplasmic reticulum. Biochem. Biophys. Res. Commun., 151, 441-449.

LATTANZIO, Jr., F.A., SCHLATTERER, R.G., NICAR, M., CAMPBELL, K.P. \& SUTKO, J.L. (1987). The effects of ryanodine on passive calcium fluxes across sarcoplasmic reticulum membranes. J. Biol. Chem., 262, 2711-2718.

LILEY, A.W. (1956). The effects of presynaptic polarization on the spontaneous activity at the mammalian neuromuscular junction. J. Physiol., 134, 427-443.

MEISSNER, G. (1986). Ryanodine activation and inhibition of the $\mathrm{Ca}^{2+}$ release channel of skeletal and cardiac sarcoplasmic reticulum. J. Biol. Chem., 261, 6300-6306.

MEISSNER, G. \& HENDERSON, J.S. (1987). Rapid calcium release from cardiac sarcoplasmic reticulum vesicles is dependent on $\mathrm{Ca}^{2+}$ and is modulated by $\mathrm{Mg}^{2+}$, adenine nucleotide, and calmodulin. $J$. Biol. Chem., 262, 3065-3073.

MITCHELL, M.R., POWELL, T., TERRAR, D.A., \& TWIST, V.W. (1984) Ryanodine prolongs Ca-currents while suppressing contraction in rat ventricular muscle cells. Br. J. Pharmacol., 81, 13-15.

NISHIMURA, M., AWANO, H. \& YAGASAKI, O. (1989). Sodium sali- cylate facilitates calcium-dependent release of transmitter at mouse neuromuscular junctions. Br. J. Pharmacol., 97, 1239-1245.

RAHAMIMOFF, R. (1968). A dual effect of calcium ions on neuromuscular facilitation. J. Physiol., 195, 471-480.

RAHAMIMOFF, R. (1976). The role of calcium in transmitter release at the neuromuscular junction. In Motor Innervation of Muscle. ed. Thesleff, S. pp. 117-149. New York, N.Y.: Academic Press.

ROUSSEAU, E., SMITH, J.S. \& MEISSNER, G. (1987). Ryanodine modifies conductance and gating behavior of single $\mathrm{Ca}^{2+}$ release channel. Am. J. Physiol., 253, C364-C368.

SU, J.Y. (1987). Effects of ryanodine on skinned skeletal muscle fibers of the rabbit. Pflügers Arch., Eur. J. Physiol., 410, 510-516.

SUTKO, J.L., ITO, K. \& KENYON, J.L. (1985). Ryanodine: a modifier of sarcoplasmic reticulum calcium release in striated muscle. Fed. Proc., 44, 2984-2988.

SUTKO, J.L. \& WILLERSON, J.T. (1980). Ryanodine alterations of the contractile state of rat ventricular myocardium. Comparison with dog, cat, and rabbit ventricular tissues. Circ. Res., 46, 332-343.

THAYER, S.A., HIRNING, L.D. \& MILLER, R.J. (1988). The role of caffeine-sensitive calcium stores in the regulation of the intracellular calcium-concentration in rat sympathetic neurons in vitro. $\mathrm{Mol}$. Pharmacol., 34, 664-673. 